\title{
USING DESIGN THINKING STRATEGIES AND VIRTUAL REALITY IN GLOBAL VIRTUAL TEAMS
}

\author{
Joy J. Godin, Georgia College \& State University, joy.godin@gcsu.edu \\ Jeannie Pridmore, University of West Georgia,jpridmor@westga.edu
}

\begin{abstract}
Design thinking is a process oriented higher-order thinking strategy that can be used to help solve managerial problems. Virtual reality offers a realistic and low-cost collaborative environment that has potential to improve the success and effectiveness of global virtual teams. This research outlines a framework for implementing design thinking strategies and virtual reality tools in global virtual teams. The factors that influence the acceptance of virtual reality tools for collaboration, the role trust plays in virtual teams, and how overall team success is impacted by design thinking strategies will all be examined in the framework.
\end{abstract}

Keywords: Design thinking (DT), Virtual Reality, Virtual Teams

\section{INTRODUCTION}

Today's businesses are looking to employee individuals with strong higher-order thinking skills. Design thinking is one higher-order thinking strategy that incorporates an iterative approach to problem solving paying close attention to business processes. With increasing workforce globalization, organizations are searching for new virtual collaboration tools to save both time and money. Virtual reality is often used for recreational purposes like gaming and socialization. The purpose of this research is to analyze the use of virtual reality with Design Thinking methods. By providing students with the experience of using virtual reality tools in realistic business case scenarios, they may be better prepared to utilize the tools to collaborate in global virtual teams.

\section{Design Thinking}

Design Thinking (DT) is defined as a user-centered approach that puts discovery and observation of human needs at the forefront of innovation, design, and development (Gruber, DeLeon, George and Thompson, 2015). DT includes a series of iterative activities such as an initial set of exploratory activities focused on gathering data to identify user needs, defining the problem, identifying the problem criteria, and followed by the generation of ideas, which are then prototyped and tested. When implementing DT strategies, participants think broadly about business processes and focus on the tasks involved in solving a business problem (Wang and Wang, 2011). DT is currently experiencing unprecedented amount of attention from practitioners and attracting increased attention from researchers for its potential to foster innovation across a vast range of organizations and issues. Prominent consulting firms, such as McKinsey, Accenture, PWC, IBM, Deloitte, and SAP have developed design thinking consultancies which is evidence of the increasing influence of design thinking in practice.

\section{Virtual Reality}

In today's global business environment, employees are often required to work virtually. While there are many collaborative technology tools, virtual reality (VR) offer a life-like level of interaction that other technologies do not. VR is an interactive computer-generated experience that takes place within a computer generated environment. It is an immersive environment that incorporates both visual, audio, and other sensory feedback that can be similar to the real world. VR allows users to simultaneously and independently explore the VR, participate in activities, and communicate with others as if they were in the real world. The promise of these life-like collaborative spaces has generated significant interest from organizations to experiment with the use of VR for cost-effective virtual global workplaces. Several firms, including Cisco, IBM, Intel, Microsoft, and Accenture, began experimenting with VRs for handling their global meetings, seminars, training programs, recruitment drives, and even social events (De Vreede et al. 2013). 


\section{Issues in Information Systems}

Volume 20, Issue 4, pp. 104-106, 2019

Even though VR technologies have the potential to transform global collaboration by facilitating real-time, media rich interactions at a significantly lower cost than other means of communication technologies, as many as nine out of ten businesses who have experimented with VR technologies failed within 18 months of their commencement (Gonsalves et al., 2008). Furthermore, the predictions of widespread adoption of VR technologies by organizations (Gartner, 2010) have not come to fruition, and to date only a few organizations have actually implemented them (Francino, 2015; Levy, 2014; Yoon and George, 2013).

Researchers have investigated perceptions of using virtual worlds for collaboration (Shivastava \& Chandra, 2018) by surveying and interviewing people who have used it for recreation and asking them about their perceptions of using it for workplace collaboration. Jacques and colleagues (2009) identified factors that influence perceptions of virtual reality teams by allowing the participants to watch videos of virtual reality teams and asking them questions about their perceptions of using virtual reality in the future for workplace collaboration. There are very few, if any, studies that incorporated design thinking strategies and virtual reality technologies in global virtual teams. Therefore, a gap in the literature has been identified that further justifies the need for the examination of using design thinking strategies in virtual reality collaboration spaces to enhance the global virtual team experiences.

\section{RESEARCH METHODOLOGY}

Our research is centered upon the following research questions: What design thinking strategies will work best for business problem solving in global virtual teams? What are the student's perceptions of virtual reality meeting spaces in global virtual teams? What roles does trust play in the success of global virtual teams?

The research hypotheses to be tested are as follows:

$\mathrm{H}_{1}$ : Design thinking strategies will help students develop solutions to business case problems.

$\mathrm{H}_{2}$ : Students will have a positive perception of using virtual reality meeting spaces for design thinking in virtual teams.

$\mathrm{H}_{3}$ : Participation in virtual reality meetings will positively influence user trust in team members working in global virtual teams.

To test these hypotheses, students will be taught design thinking strategies while working in global virtual teams. Virtual reality collaboration spaces will be used for virtual team meetings and design thinking training. Students will meet virtually first and then face-to-face to develop a solution to a business problem using design thinking strategies. The study will be part of a study abroad experience for business students at three universities, two in the U.S. and one in Europe. The students will meet in virtual reality collaboration spaces for team building exercises and for their initial meeting with a business that will reveal a real business case problem. Next, the students will meet face-to-face to incorporate design thinking strategies to develop a solution for the business' case problem. The team will then present their solution to the business.

Students will complete a survey before they participate in the study and then again after they participate to identify their perceptions of working in global virtual teams and how using the virtual reality meeting space impacted their trust in their team members. They will also be asked about their perceptions of using design thinking strategies for developing solutions to the business problem.

Survey items will include both qualitative and quantitative questions for data analysis. Observations will also serve as qualitative data as researchers will observe the participants as they incorporate the Design Thinking methods in the virtual environment and in person. The hypotheses will be evaluated by using qualitative methods with open ended questions and student observations. T-tests and ANOVA will be used to evaluate the pre- and post-test surveys. 


\section{SUMMARY}

We put forth that the evaluation of both the structural elements of virtual reality technologies and the aspects needed for design thinking will lead to the creation of a framework that will aid in and ensure success in the implementation and user adoption of virtual reality for design thinking. This research seeks to put collaborative groups at the center of the research process to understand how distinct virtual reality features can support design thinking activities. We will draw from best practices in teaching Design Thinking strategies (Doorley et al., 2018) and findings and observations from past research of virtual teams (Godin et. al, 2017; Pridmore \& Godin, 2018).

\section{REFERENCES}

De Vreede, T., Nguyen, C., De Vreede, G. J., Boughzala, I., Oh, O., \& Reiter-Palmon, R. (2013, October). A theoretical model of user engagement in crowdsourcing. In International conference on collaboration and technology (pp. 94-109). Springer, Berlin, Heidelberg.

Doorley, S., Holcomb, S., Klebahan, P., Segovia, K. \& Utley, J. (2018). Design Thinking Bootcamp, d.school at Stanford University, https://dschool.stanford.edu/resources/the-bootcamp-bootleg.

Francino, Y. 2015. "Virtual Worlds Used as Business Collaboration Tools," TechTarget (http://searchsoftwarequality.techtarget.com/feature/Virtual-worlds-used-as-business-collaborationtools).

Gartner Research. (2010), "Hype Cycles 2010”, available at: http://www.gartner.com/technology/research/hypecycles/report/index.jsp (accessed 13 April 2010).

Godin, J., Leader, L., Gibson, N., Marshall, B., Poddar, A., \& Cardon, P. W. (2017). Virtual teamwork training: factors influencing the acceptance of collaboration technology. International Journal of Information and Communication Technology, 10(1), 5-23.

Gonsalves, A., Ternier, S., De Vries, F., \& Specht, M. (2012). Serious games at the UNHCR with ARLearn, a toolkit for mobile and virtual reality applications.

Gruber, M., De Leon, N., George, G., \& Thompson, P. (2015). Managing by Design.

Jacques, P. H., Garger, J., Brown, C. A., \& Deale, C. S. (2009). Personality and virtual reality team candidates: The roles of personality traits, technology anxiety and trust as predictors of perceptions of virtual reality teams. Journal of Business and Management, 15(2), 143.

Levy, K. 2014. "A Night in Second Life: The Legendary Virtual World Is Still around but Getting Weirder," Business Insider, August 2 (http://www.businessinsider.sg/second-life-today-2014-7/\#.VyB-jNR97IU).

Pridmore, J. \& Godin, J. (2018). Investigation of virtual teams and serious games, Journal of Computer Information Systems, DOI: 10.1080/08874417.2018.1443293.

Srivastava, S. C., \& Chandra, S. (2018). Social presence in virtual world collaboration: An uncertainty reduction perspective using a mixed methods approach. MIS Quarterly, 42(3), 779-803.

Wang, S., \& Wang, H. (2011). Teaching design thinking through case analysis: Joint analytical process. Decision Sciences Journal of Innovative Education, 9(1), 113-118.

Yoon, T. E., \& George, J. F. (2013). Why aren't organizations adopting virtual worlds? Computers in Human Behavior, 29(3), 772-790. 